\title{
Fruit Cluster Pruning of Tomato in an Organic High-Tunnel System
}

\author{
Brian A. Mitchell ${ }^{\mathbf{1}}$ and Mark E. Uchanski \\ Department of Horticulture and Landscape Architecture, Specialty Crops \\ Program, Colorado State University, Fort Collins, CO 80523
}

Adriane Elliott

Department of Soil and Crop Sciences, Colorado State University, Fort Collins, CO 80523

Additional index words. fruit load management, fruit thinning, truss pruning, hoop house

\begin{abstract}
This research assessed fruit load management and production techniques for cultivating indeterminate tomatoes in a high tunnel under intensive organic management. The successful production of high-quality, high-yielding crops is important for fruit and vegetable producers, especially growers using high tunnels. High tunnels are well-suited to organic farming and can be used to grow many valuable specialty crops. Fruit load management is practiced in fruit production (e.g., apples, peaches, and grapes), but there is lack of consensus concerning the effectiveness of fruit cluster pruning on tomato (Solanum lycopersicum) and its impact on fruit yield, quality, and marketability. In addition, there is no published research on tomato cluster pruning in certified organic systems or intensively managed high tunnels (e.g., densely planted, trellised, vegetatively pruned plants) for the Front Range of Colorado. In 2016 and 2017, a randomized complete block design was used to test the effects of cluster pruning within a high tunnel on certified organic land at Colorado State University's (CSU's) Agricultural Research, Development, and Education Center, South. Two treatments and three tomato cultivars were selected for the study; the treatment-cultivar combinations were replicated six times within a high tunnel. The treatments involved reducing fruit loads to three fruit and six fruit per cluster, whereas plants with unpruned clusters, which naturally developed as many as $\mathbf{1 0}$ fruit, served as the control. Tomato cultivars evaluated were 'Cherokee Purple', a widely studied heirloom, and two hybrids: 'Jet Star' and 'Lola'. Parameters measured included total yield, individual fresh fruit weight, soluble solids content (SSC), marketable yield, and nonmarketable yield. Individual fresh fruit weight increased for both hybrids in the three-fruit treatment, averaged over two growing seasons. 'Cherokee Purple' did not respond to the cluster pruning treatments. There was no decrease in total yield, across all cultivars, between treatments and the unpruned control. However, 'Jet Star' yielded more than the other two cultivars. In addition, SSC and marketability measurements were more influenced by cultivar than cluster pruning treatments. 'Lola' had a significantly greater SSC than the other two cultivars. 'Jet Star' had the greatest marketable yields of all cultivars tested whereas 'Cherokee Purple' produced greater nonmarketable (cull) yields. Cluster pruning produced larger organic tomatoes without reducing yield or quality for two of the three cultivars used in the study. Cultivar selection remains one of the greatest factors in determining yield, quality, and marketability of a crop.
\end{abstract}

A pound of organic heirloom tomatoes costs $\$ 5$ at the Larimer County Farmers' Market in Fort Collins, CO. Nonorganic heirlooms range from $\$ 2-6.50 / \mathrm{lb}$, whereas other tomatoes at the local market, both organic and noncertified, range from \$3-5/ lb (Colorado Department of Agriculture, 2018). Trends in the national fresh tomato

Received for publication 10 Aug. 2018. Accepted for publication 17 Dec. 2018.

We thank the Department of Horticulture and Landscape Architecture, the Agricultural Experiment Station, and the Statistical Laboratory at Colorado State University, Fort Collins, CO.

${ }^{1}$ Corresponding author. E-mail: Brian.Mitchell@ colostate.edu.

This is an open access article distributed under the CC BY-NC-ND license (https://creativecommons. org/licenses/by-nc-nd/4.0/). use of a high tunnel is one of the most successful tactics for growing high-quality, high-yielding, and valuable crops. A high tunnel, or hoop house, is a temporary, movable, or semipermanent structure that may be single- or multispan (i.e., many connected structures). High tunnels may be covered in polyethylene film, insect netting, or shadecloth, or left bare, and are typically unheated and passively ventilated. Crops are usually planted directly in the soil within high tunnels, although containers and soilless media are used occasionally. A high tunnel provides multiple benefits for the grower over openfield cultivation, including season extension, insect exclusion, reduced disease pressures, protection from environmental damage (such as hail avoidance), and greater marketable yields. Furthermore, high tunnels provide valuable services in organic agricultural systems because they can improve the quality and yield of vegetables over open-field growing systems (Rogers and Wszelaki, 2012).

Tomatoes are the most popular and often the most profitable plant for high-tunnel growers. They are an excellent crop choice as a result of their high value in the fresh market and the crop's ability to produce high yields (Mefferd, 2017). Indeterminate tomatoes produce fruit throughout the growing season and benefit from both the high tunnel environment and trellising. Indeterminate cultivars of tomato allow growers to meet consumer demand consistently. High tunnels provide a protected microclimate and longer harvests, and allow for continuous production of fresh fruit (Rogers and Wszelaki, 2012).

Fruit cluster pruning of tomatoes has been shown to influence total yield, marketability, individual fruit fresh weight, and various indicators of quality, such as dry matter and SSC. Fruit cluster pruning is used to limit the number of fruit per cluster and reduce competition to increase individual fruit weight (Hanna, 2009). Studies across the world (Turkey, South Africa, the Netherlands, Italy, and the United States) have produced conflicting results on the efficacy of cluster pruning of tomatoes in various controlled environments (Table 1). Specifically, there is a lack of research on cluster pruning in intensively managed organic systems, in high tunnels, and on the Front Range of Colorado.

Cultivar selection is a critical component for growers who are concerned about the maximization of yield, the fresh market appeal of their products, and the general performance (e.g., pest and disease resistance, physiological traits, and quality) of their crops (Healy et al., 2017). Growers evaluate cultivars for their desired fruit qualities, shelf life and storage characteristics, and potential yield (Hanna, 2009). Although most hybrid cultivars of tomatoes are bred for increased yield, visual appeal, and shipping durability, open-pollinated heirloom cultivars of tomatoes are valued for their unique colors, shapes, flavors, and legacies. However, heirloom tomatoes generally lack uniformity, have thinner skins, lack disease 
resistance, and have lower yields than most modern hybrid cultivars (O'Connell et al., 2012).

$\mathrm{SSC}$, represented in ${ }^{\circ} \mathrm{Brix}$, is a common measurement used by tomato growers, processors, and fresh market growers. In the fresh market, soluble solids levels provide an approximation of how sweet the tomato may taste; however, many components define the overall flavor of each tomato, including sugars, acids, volatiles, and other compounds. An SSC measurement in ${ }^{\circ}$ Brix, using a refractometer, is a quick, reliable, and inexpensive field test for quality. Although measurements can be an early indication of sweetness and flavor, SSC can fluctuate as a result of many factors, including crop, cultivar, maturity, growing environment, and storage conditions (Kleinhenz and Bumgarner, 2015). Healy et al. (2017) found that tomatoes had a greater SSC when grown in a high tunnel compared with open-field production.

Tomato vegetative growth is pruned regularly when the crop is grown in a controlled environment. Tomato plants develop side shoots in their leaf axils; these axillary shoots will continue to grow and produce leaves and fruit clusters if not removed. Axillary shoots should be removed regularly (often repeatedly) to maintain a single leader, or main stem. This is an effective way to maximize production space, and can improve the yield and quality of tomatoes (Maboko et al., 2011). It is also common practice in intensive greenhouse operations to remove any leaves below the lowest ripening cluster. The lower canopy receives little sunlight and is unnecessary for continued plant growth and fruit production. In addition, the removal of superfluous leaves allows the plant to allocate more energy to vertical growth and fruit development while also reducing disease pressure by maximizing air flow.

The overall objective of this study was to evaluate the differences between two tomato fruit cluster pruning treatments and a control on three cultivars of indeterminate tomatoes: Cherokee Purple, Jet Star, and Lola. We hypothesized that 1) cluster pruning would decrease total yield, 2) cluster pruning would increase the quality of the organic tomatoes, and 3 ) cultivars would respond differently to the cluster pruning treatments for the parameters analyzed in the study. To test these hypotheses, differences between cluster pruning treatments and cultivar performance were assessed in terms of total yield, individual fresh fruit weight, SSC, marketable yield, and nonmarketable yield.

\section{Materials and Methods}

Site description, high-tunnel description, and cultural practices. This study was conducted in semipermanent high tunnels on certified organic land at CSU's Agricultural Research, Development, and Education Center, South (ARDEC S.) (40.610012, -104.993979; altitude: $1523 \mathrm{~m}$ ) in 2016 and 2017. CSU in Fort Collins, $\mathrm{CO}$, has $557 \mathrm{~m}^{2}$ of high-tunnel space across seven structures dedicated to research in

Table 1. A literature summary of tomato fruit cluster pruning controlled environments.

\begin{tabular}{llllc}
\hline & \multicolumn{1}{c}{ Site } & \multicolumn{1}{c}{$\begin{array}{c}\text { Growing } \\
\text { environment }\end{array}$} & \multicolumn{1}{c}{ Tomato cultivar } & $\begin{array}{c}\text { Fruit no./ } \\
\text { cluster }\end{array}$ \\
\hline Saglam and & Turkey & Low tunnel & Vivia & $4,6,8$ \\
Yazgan (1999) & & & & Geronimo, Trust, Quest \\
Manna (2009) & Louisiana, U.S. & Greenhouse & 3,4 \\
Maboko et al. (2011) & South Africa & Hydroponic/shade & FA593 & 4,6 \\
Fanasca et al. (2007) & Netherlands & Greenhouse & Cederico/Maxifort rtstk. & 3,6 \\
\hline
\end{tabular}
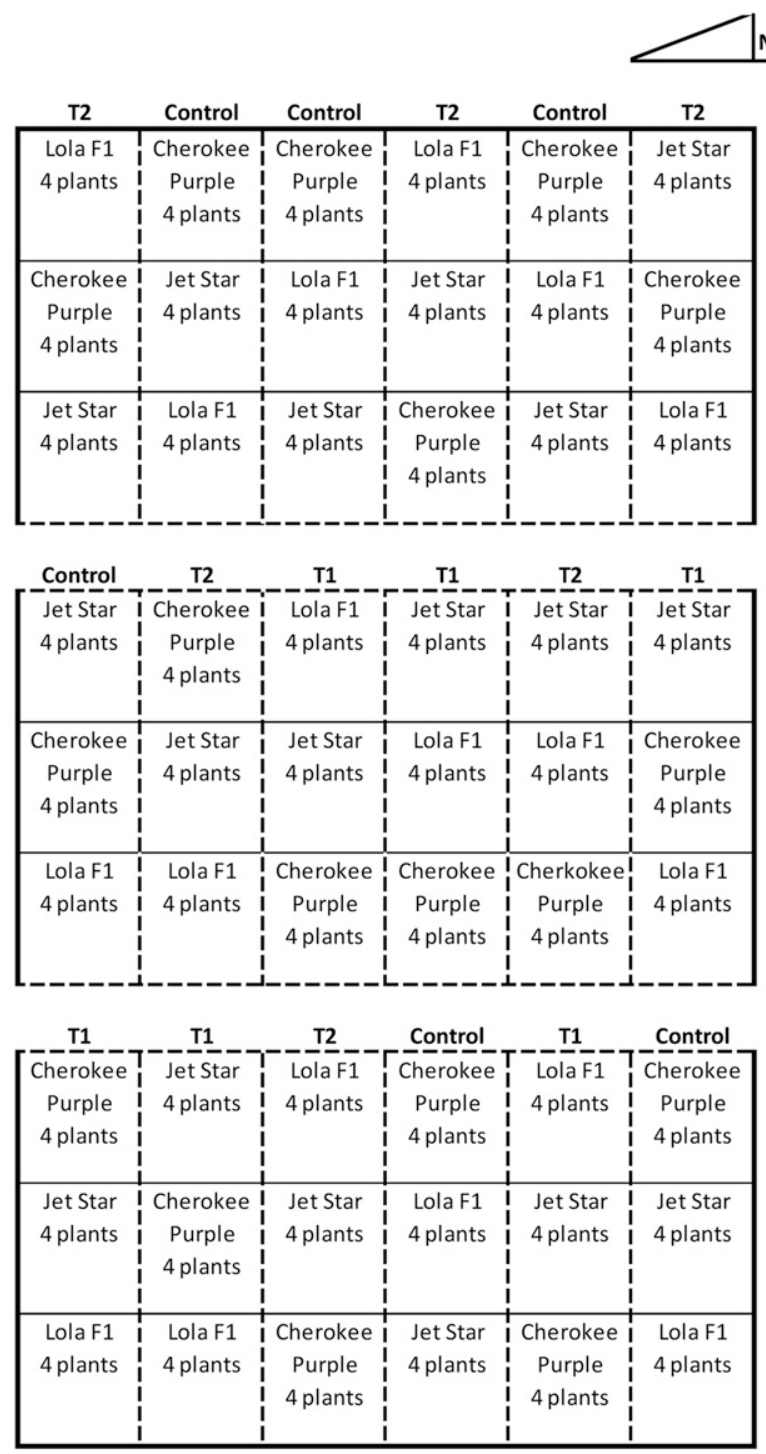

$\begin{array}{llllll}\text { BLOCK } 1 & \text { BLOCK } 2 & \text { BLOCK } 3 & \text { BLOCK } 4 & \text { BLOCK } 5 & \text { BLOCK } 6\end{array}$

Fig. 1. The randomized complete block design used within the high tunnel in 2016.

vegetable crop breeding, vegetable cropping systems, cover crops, and cyanobacterial fertilizer (Carey et al., 2009). The soil in the high tunnels at ARDEC S. is classified as a Nunn clay loam (Soil Survey Staff, Natural Resources Conservation Service, U.S. Department of Agriculture, 2018). Soil samples were collected to a depth of 20 to $30 \mathrm{~cm}$ each year before planting and were tested at the CSU Soil, Water and Plant Testing Laboratory. Soil was analyzed for $\mathrm{pH}$, salts, lime, texture, organic matter, and nutrient content to deter- mine recommended preplanting compost application and fertilizer rates during the growing season.

The certified organic high tunnels were prepared each year by tilling the soil 0.15 to $0.30 \mathrm{~m}$ deep with a rototiller (Harvester 722 ; BCS, Portland, OR). All practices aligned with U.S. Department of Agriculture guidelines for organic production. After tillage, 1.2 to $1.5 \mathrm{~m}^{3}$ of plant-based compost (A-1 Organics, Eaton, $\mathrm{CO}$ ) was incorporated into the topsoil. Six lines of drip tape $13.7 \mathrm{~m}$ long 
were run lengthwise within the high tunnel, corresponding to the blocking described later. The drip tape was attached to $1.9-\mathrm{cm}$ black plastic irrigation headers at each end of the high tunnel and emitted $500 \mathrm{~L} / \mathrm{h} / 100 \mathrm{~m}$. The high tunnels were $6.1 \mathrm{~m}$ wide, $15.2 \mathrm{~m}$ in length, and had twin-walled polycarbonate end walls with a $1.8-\mathrm{m}$ square roll-up door on one side. Insect netting was used on both high tunnels and was attached to the sides with a system commonly used in the nursery and greenhouse industry. The netting was fine meshed and served to exclude insect pests.

The high tunnels had six metal cables running from the end bows that functioned as a trellising system. Extra metal cables were strung perpendicular to the six main trellis cables for additional support. Trellising spools with white twine and hooks on each end were used to train the single-leader tomatoes. Trellising clips were used to attach the plants to the twine and were added every 15 to $30 \mathrm{~cm}$ throughout the growing season. Tomato fruit cluster supports were used to redistribute fruit weights from plant stems to the trellises and were added as fruit ripened. The reduction of the number of fruit per cluster can increase fruit size dramatically, and the weight of large fruit can cause damage to the cluster and stem (Saglam and Yazgan, 1999).

Water was supplied to the plants with a drip irrigation system. The tomatoes were watered once or twice daily for 15 to $30 \mathrm{~min}$ using an irrigation controller. In 2016, Organic Materials Review Institute (OMRI)-approved fish emulsion fertilizer (Alaska Fertilizer 5-11; Pennington, Renton, WA) was used for supplemental nitrogen fertilization throughout the growing season and was applied every 2 to 3 weeks from July to mid September. In 2017 , the same fertilizer was used from mid June to mid July. A different fish emulsion product (Drammatic "One" Plant Food 4-4-0.5; Dramm Corporation, Manitowoc, WI) was used from August until mid September. The fertilizer change was an economic decision; however, all treatments received the same rates of nitrogen, phosphorus, and potassium fertilizers. Organic fertilizers were applied through the irrigation system using a siphon injector or by hand with a watering can. In mid July 2017, a small fertilizer injector (Dosatron, Clearwater, FL) replaced the previous system. Woven weed fabric was used to control weeds within the high tunnel. Weeds were pulled by hand or mowed in and around the high tunnel as needed. Predominant weeds included bindweed, canada thistle, and grasses.

The tomato cultivars evaluated were Cherokee Purple, a popular heirloom used widely in research; Jet Star, an $\mathrm{F}_{1}$ hybrid cultivar previously trialed at CSU's CSA program; and Lola, an $\mathrm{F}_{1}$ hybrid cultivar bred for intensive greenhouse cultivation, which differs from high-tunnel production. Seeds were sown in a greenhouse on 17 May 2016 and 13 Apr. 2017. The seedlings were hardened off in a shaded, protected outdoor space for a week before planting. The seedlings were transplanted into a high tunnel in June

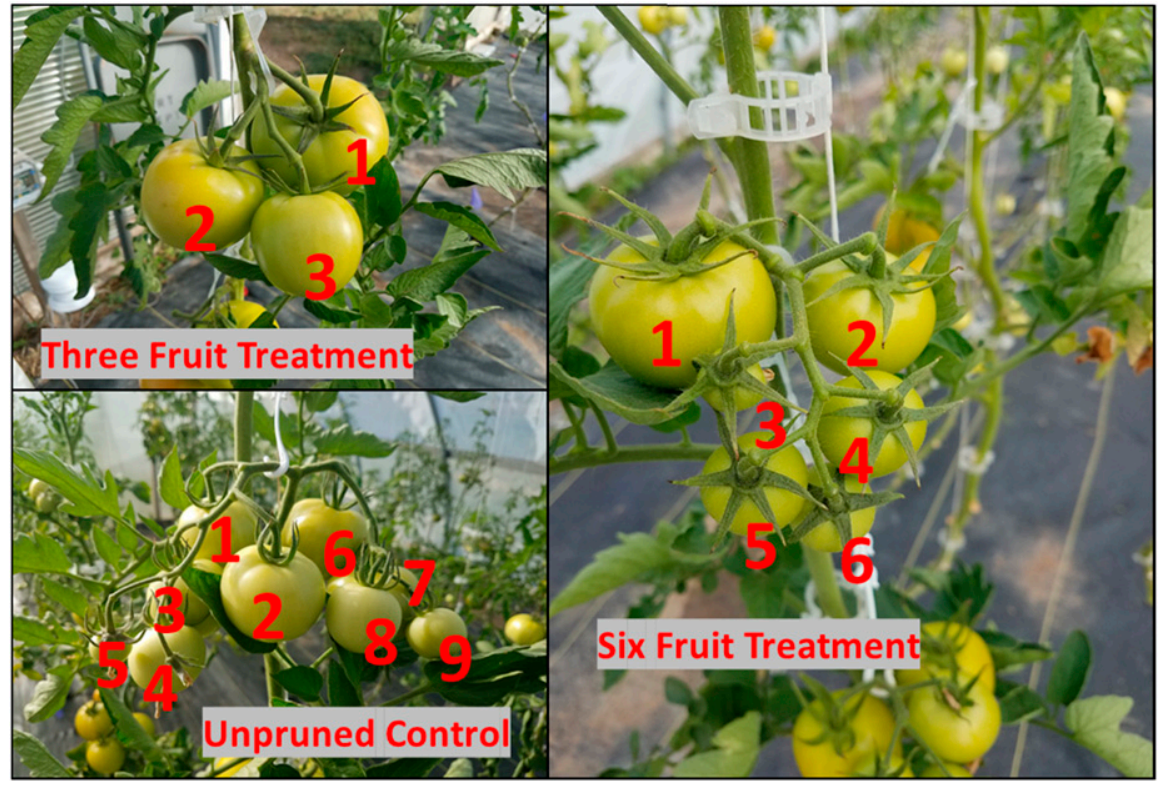

Fig. 2. A visual representation of the cluster pruning treatments (on 'Lola') in the study. Clockwise from top left: three-fruit treatment, six-fruit treatment, and an unpruned cluster (control), which could set up to 10 fruit, depending on the cultivar and growing season.

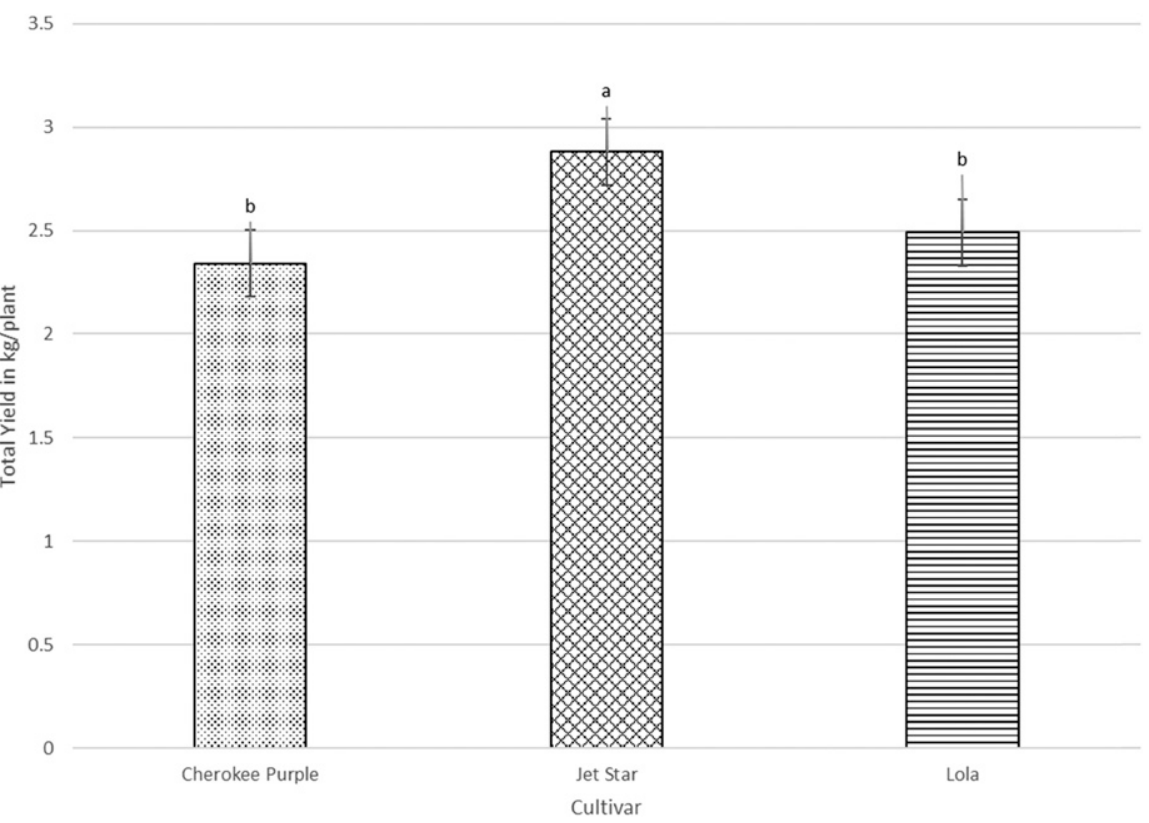

Fig. 3. 'Jet Star' had a greater total yield than both 'Cherokee Purple' and 'Lola' when results were averaged over treatment, year, and block. Data are shown as mean $\pm \mathrm{sE}$. Dissimilar letters represent differences at $\alpha=0.05$.

during both years of the study. All tomato plants were trained to have a single leader beginning on 8 July 2016 and 19 June 2017. Fruit clusters would often develop stems or leaves that would to grow to obscure and possibly damage the cluster; this excessive vegetative growth was pruned off all plants during the study. Leaves were removed throughout the growing season as they senesced, showed signs of disease, touched the soil or weed barrier (to manage disease transmission preventively), or if they hampered data collection or harvesting. Sufficient leaf cover was left to shade de- veloping and ripening fruit to prevent sunscald and uneven ripening. Nitrile gloves were worn while pruning, and a $70 \%$ ethanol solution was sprayed on small pruners between plants for good sanitation. It was necessary to prune side shoots, unnecessary leaves, and excess vegetative growth on fruit clusters once a week. A pollination wand (Garden Pollinator model VBP-01; VegiBee, Maryland Heights, MO) was used to manage pollination. It was used in the mornings every other day on medium speed near each mature flower on the cluster. 
Experimental design, cluster pruning treatments, and harvests. A randomized complete block design was used for this experiment (Fig. 1). The high tunnels at ARDEC S. are oriented lengthwise east to west; in northern latitudes, east-west orientation is commonly used to maximize light interception in the winter. Six blocks ran east to west; blocking was used to compensate for known variability in the growing space within the high tunnel. There were $0.9-\mathrm{m}$ spaces between blocks and from blocks to the hightunnel sides. Clusters were reduced to three fruits in one treatment and six fruits in the second treatment. Plants in the control had unpruned clusters, producing as many as 10 fruit per cluster (Fig. 2). The two cluster pruning treatment groups and the control groups were assigned randomly within each block. Treatments within blocks were separated by a $1.2-\mathrm{m}$ walkway. Within each treatment, four-plant groupings of the three indeterminate tomato cultivars were assigned randomly. Plants within treatments were spaced $0.3 \mathrm{~m}$ apart. In 2017, the experimental design was the same, but the experiment was conducted in an adjacent high tunnel to ensure an adequate crop rotation per certified organic guidelines. The two treatments and the control were rerandomized within the six blocks; the three cultivar subsamples were rerandomized within each treatment.

Fruit were pruned from clusters when they were marble size (Maboko et al., 2011). The fruit most proximal to plant stems were selected to remain on the cluster, and distal fruit were removed when a choice was available. King fruit (the result of two or more flowers fusing together) were was identified and removed from clusters. These fused fruit are often first to develop and are often larger than average, misshapen, and unmarketable. King fruit were particularly an issue with 'Cherokee Purple' in our study. Cluster pruning was done once a week throughout the growing season, from 29 July to 28 Sept. 2016 and from 7 July to 27 Sept. 2017.

Harvests were conducted to emulate a grower harvesting ripe fruit for the local fresh market. In 2016, there were 11 harvests, with the first harvest on 30 Aug. 2016 and the final one on 7 Oct. 2016. In 2017, there were 14 harvests, with the first harvest on 31 July 2017 and the last harvest taking place on 6 Oct. 2017. The data collected for each fruit included the block number, treatment, plant number within treatment and cultivar, cluster number proximal to distal, tomato number and position on each cluster, whether the fruit was marketable, notes on physiological disorders or damage, and fruit fresh weight. Marketability was determined using a combination of the U.S. Standards for Grades of Fresh Tomatoes and local market standards (U.S. Department of Agriculture, 1991).

On 23 Sept. 2016 and 8 Sept. 2017, specific harvests were conducted to assess the SSC of fruit using the ${ }^{\circ}$ Brix scale, which ranges from 0 to 56 . Fruit were collected during the peak of the harvest season - a standard practice when

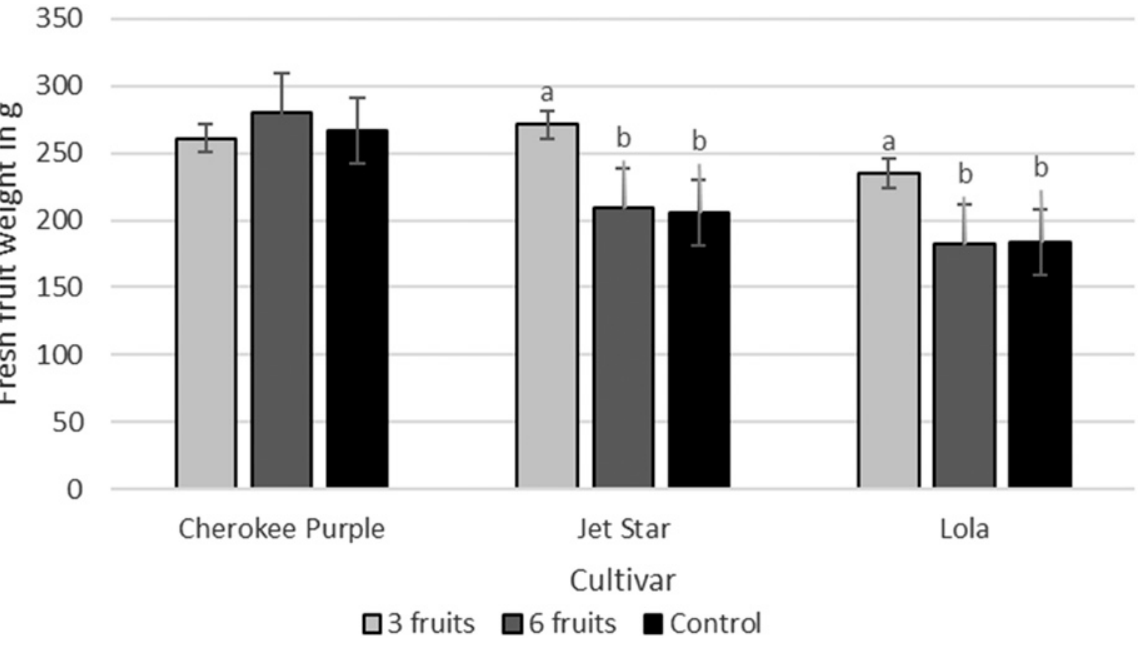

Fig. 4. The treatment effect of cluster pruning on individual fresh fruit weight of organic high-tunnel tomatoes. 'Jet Star' and 'Lola' produced larger fruits with the three-fruit treatment. Data are shown as mean \pm SE. Dissimilar letters represent differences at $\alpha=0.05$ and results are averaged over year and block.

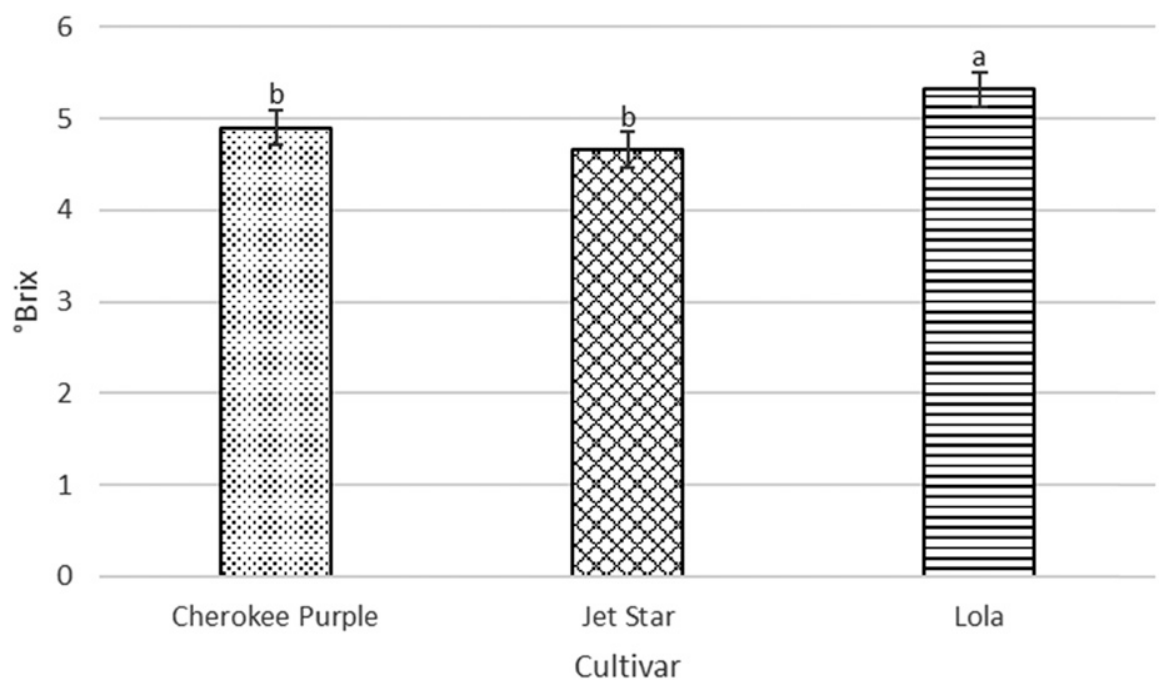

Fig. 5. The cultivar effect on soluble solids content, where 'Lola' measured greater on the ${ }^{\circ}$ Brix scale than both 'Cherokee Purple' and 'Jet Star'. Data are shown as mean \pm SE. Dissimilar letters represent differences at $\alpha=0.05$ and results are averaged over treatment, year, and block.

measuring SSC. Representative fruit were harvested from plants within each experimental unit. The samples were sealed in plastic bags and stored in a freezer at $30^{\circ} \mathrm{C}$. The fruit, when thawed, were mashed and combined to attain an aggregate measure. The pulp was strained with cheesecloth and the juice was assessed using a refractometer. SSC was measured and recorded for each of the 54 experimental units each year. An acceptable range for fresh market tomatoes in Colorado is 3.5 to 5.3 . The ${ }^{\circ}$ Brix scale is used to assess harvest readiness and to determine quality in the field and during processing, and represents a product's potential sweetness and flavor (Kleinhenz and Bumgarner, 2015).

Statistical analyses. A two-way factorial treatment structure with subsampling was used in our study. Analyses explored interactions and main effects of treatment and cultivar. If an interaction was found to be significant at $\alpha=0.05$, additional tests were conducted. The separate linear models included block, year, treatment, and cultivar as categorical variables, and allowed interaction between treatment and cultivar effects. Response variables were total yield, individual fresh fruit weight, SSC measured in ${ }^{\circ}$ Brix, marketable yield, and nonmarketable yield. Blocks were treated as a random effect whereas year, treatment, and cultivar were treated as fixed effects in each model. The experimental unit consisted of four-plant groupings by cultivar that represented each treatment and cultivar combination. Years were combined for a total of 12 replications for the study; the same two treatments and three cultivars were used both years.

All data were analyzed using $\mathrm{R}$ statistical software (R Core Team, 2016) and R Studio (version 1.0.136). Yields was assessed by taking the mean yield for the plants in each experimental unit. Fresh fruit weight was calculated by taking the mean yield of the individual fruit 
from each plant and taking the average mean fruit weight for the entire subsample. SSC was calculated as described previously. An analysis of variance (ANOVA) and pairwise comparisons were used to compare the differences in the least-squared means of the response variables. The Type III ANOVA used the Kenward-Roger approximation for $\mathrm{df}$ whereas $t$ tests used Satterthwaite approximations to df. Pairwise comparisons were used to separate leastsquared means by treatment and cultivar, and results were averaged over year. Default $P$ value adjustments for pairwise comparisons were made using the Tukey method for comparing a family of three estimates. The significance level was set at 0.05 for all analyses.

\section{Results and Discussion}

Total yield. There was a significant effect of cultivar $(P<0.01)$ for total yield, as the three cultivars performed differently, averaged over year and treatment (Fig. 3). There was no interaction between treatment and cultivar, and no treatment main effect was observed for total yield in our experiment. The results for total yield were comparable to the findings of Maboko et al. (2011), whose cluster pruning did not have a significant effect on tomato total yield.

Cultivar selection had more impact on total yield than a reduction in the fruit load per cluster. Despite its compact yet indeterminate growth habit, 'Jet Star' consistently produced highly acceptable fruit regardless of treatment, and outperformed both cultivars when considering total yield. 'Jet Star' proved to be a good selection for organic high-tunnel production in our study, as demonstrated in the context of total yield and marketability.

Individual fresh fruit weight. An interaction between treatment and cultivar was found in the responses for individual fresh fruit weight $(P<0.01)$. Significant differences were found for both the main effect of treatment $(P<0.01)$ and cultivar $(P<0.01)$. Both hybrid tomato cultivars, Jet Star and Lola, produced larger fruits with three-fruit clusters than with six-fruit or unpruned clusters (Fig. 4). 'Jet Star' fresh fruit weight in the three-fruit treatment was $32 \%$ greater than the control and $31 \%$ greater than the six-fruit treatment. The fresh fruit weight for 'Lola' in the three-fruit treatment was $27 \%$ greater than the control and $29 \%$ greater than the six-fruit treatment. There were no treatment differences in the fresh fruit weight of 'Cherokee Purple' tomatoes.

Pairwise comparisons for the effect of cultivar showed that 'Cherokee Purple' plants with unpruned clusters produced larger fruit $(P<0.01)$ than both 'Jet Star' ( $23 \%$ smaller) and 'Lola' (31\% smaller). Results were similar for the six-fruit treatment: 'Cherokee Purple' produced larger individual fruits than both hybrids $(P<$ $0.01)$. With six-fruit clusters, 'Cherokee Purple' fresh fruit weight was $34 \%$ greater than 'Jet Star' and 54\% greater than 'Lola'. Under the three-fruit cluster pruning treatment, 'Jet Star' produced a fresh weight

3

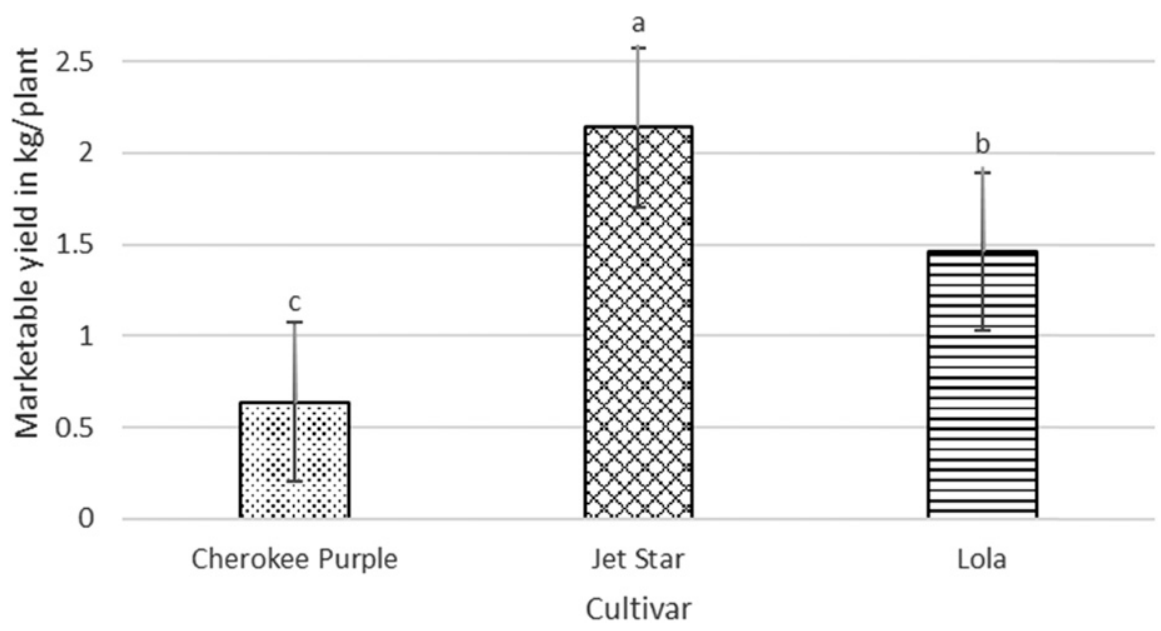

Fig. 6. 'Jet Star' produced more marketable yield than 'Lola', which produced more marketable fruits than 'Cherokee Purple'. Data are shown as mean \pm SE. Dissimilar letters represent differences at $\alpha=0.05$ and results are averaged over treatment, year, and block.

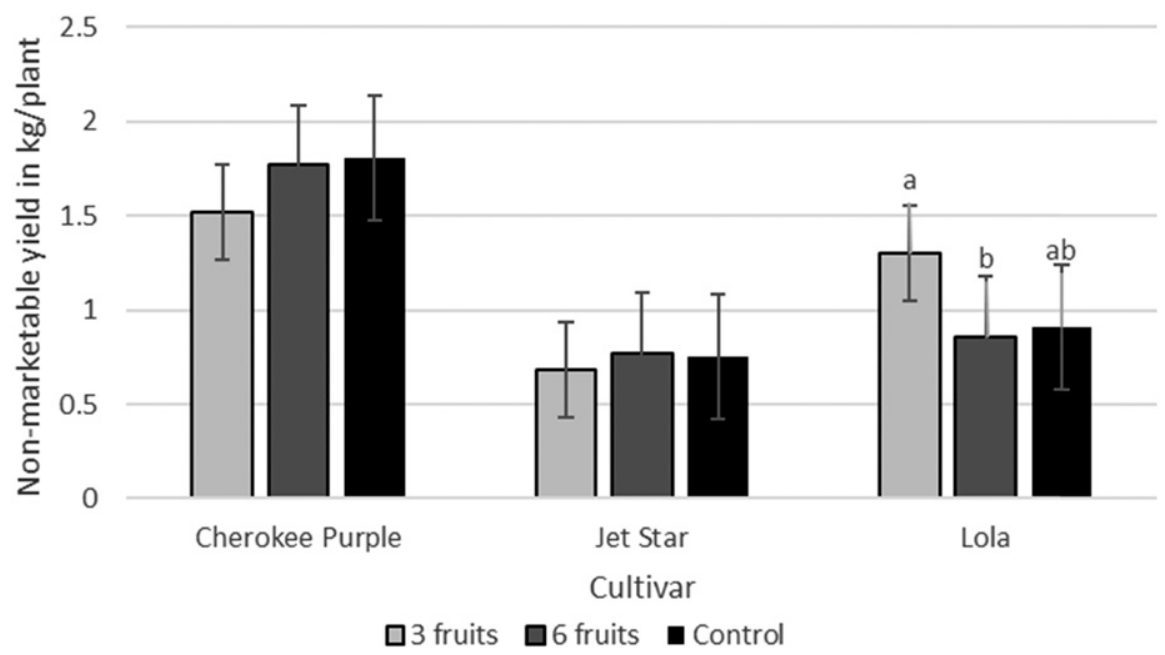

Fig. 7. The cluster pruning treatment effect on nonmarketable yield. The three-fruit treatment increased nonmarketable yield for 'Lola' in our study. Data are shown as mean \pm SE. Dissimilar letters represent differences at $\alpha=0.05$ and results are averaged over treatment, year, and block.

measurement $16 \%$ greater than 'Lola' ( $P<$ 0.01). 'Cherokee Purple' clusters with three fruit almost produced larger fruit than 'Lola' in the same treatment $(P<0.07)$, but results were not significant at $P=0.05$.

Pruning tomato clusters to three fruit increased fruit weight significantly for two of the three cultivars in our study. This is similar to previous findings, in which a reduced fruit load per fruit cluster resulted in greater individual fresh fruit weights (Hanna, 2009; Saglam and Yazgan, 1999). The hybrid cultivars Jet Star and Lola, demonstrated a strong response to the three-fruit treatment, producing fruit that were one-third larger than either the six-fruit treatment and the control. Cluster pruning likely reduces competition for plant resources and thus increases fruit weight (Hanna, 2009).

'Cherokee Purple' showed no response to the cluster pruning treatments for the parameter of fresh fruit weight. The fruit produced by this heirloom tomato cultivar were often very large, regardless of the number of fruit per cluster. 'Cherokee Purple' with unpruned clusters produced larger fruits than both hybrids, which is likely explained by their proclivity for producing large fruit. The response was similar with the six-fruit treatment; often, clusters did not produce more than three or four fruit, so there was little difference between the six-fruit treatment and the control.

Soluble solids content. For SSC, no interaction was found between treatment and cultivar. Neither was there a significant main effect of treatment; SSC was unaffected by cluster pruning. However, there was a significant main effect of cultivar $(P<0.01)$; 'Lola' had a significantly greater SSC than the other two cultivars (Fig. 5). A larger tomato-from a three-fruit cluster, for example - might be expected to have greater water content and reduced sugars compared with a smaller fruit. When fruit load and competition for plant resources are reduced and the sink-to-source 
ratio decreases, more photosynthates, acids, and other compounds are available for the remaining fruit (Fanasca et al., 2007).

Marketable yield. No interaction was found between treatment and cultivar for the response of marketable yield. There was no significant main effect of treatment, and marketable yield did not differ between the two growing seasons. However, regarding marketability, there was a significant main effect of cultivar $(P<0.01)$ and notable differences between the three cultivars. 'Jet Star' produced significantly greater marketable yields than 'Lola', which in turn produced significantly greater marketable yields than 'Cherokee Purple' (Fig. 6). In our study, cultivar selection was the most important factor when looking at marketable yield. These results contradict studies in which cluster pruning increased marketable yield (Hanna, 2009; Saglam and Yazgan, 1999).

Nonmarketable yield. An interaction was found between cluster pruning treatments and cultivar for nonmarketable yield $(P=$ $0.04)$. The main effect of cultivar was also significant $(P<0.01)$. Exploring the main effect of cultivar with pairwise comparisons, a significant difference $(P=0.04)$ was found between the three-fruit and six-fruit treatments for 'Lola'. The six-fruit treatment reduced nonmarketable yield by $34 \%$ compared with the three-fruit treatment; therefore, the three-fruit cluster treatment increased the nonmarketability of fruit compared with the six-fruit cluster pruning treatment (Fig. 7).

Potential nonmarketable yield, or cull yield, is important to consider when developing production methods and choosing cultivars to grow for direct markets. 'Cherokee Purple' produced fruit prone to various types of cracking and problems like catfacing and irregular shaping. 'Lola' fruit increased in size with the three-fruit treatment, yet frequently developed large radial cracks; these cracks could host fungal infections and render the fruit unmarketable while still on the vine. 'Jet Star' produced the smallest nonmarketable yields (had more marketable fruit) and only showed physiological problems after periods of rain, as in 2017 when ripening fruit split right before harvest.

\section{Conclusions and Observations}

The purpose of our study was to determine whether cluster pruning would improve the yield and quality of three different cultivars of tomato grown in a certified organic high tunnel. Cluster pruning treatments did not increase or decrease total yield compared with the control; organic high tunnel growers could reduce fruit loads per cluster and maintain yield, depending on their cultivar selection. 'Jet Star' produced greater total yields, averaged over treatment, than both 'Cherokee Purple' and 'Lola'. Individual fresh fruit weight increased for the two hybrid cultivars in the three-fruit treatment. Cultivar had an impact on SSC, with 'Lola' having greater SSC than the other two cultivars. Marketability and nonmarketability were determined largely by cultivar attributes, weather conditions, and insect and disease pressure, and less by treatment, as observed in other studies. 'Lola', a hybrid cultivar used in commercial greenhouse production, did not perform well in the context of our study: Fruit did not ripen in a timely manner and nonmarketable yield increased with the three-fruit treatment. In summary, larger tomatoes were produced in our study by cluster pruning without a reduction in yield or quality for two of the three cultivars tested. Also, the yield, quality, and marketability of the organic tomato crops were more influenced by the effects of cultivar than cluster pruning treatments.

\section{Literature Cited}

Carey, E.E., L. Jett, W.J. Lamont, Jr., T.T. Nennich, M.D. Orzolek, and K.A. Williams. 2009. Horticultural production in high tunnels in the United States: A snapshot. HortTechnology 19:37-43.

Colorado Department of Agriculture. 2018 Farmers' market price reports: 2015 Season averages-Old Town Farmers' Market-Fort Collins. 8 Aug. 2018. <https://www.colorado. gov/pacific/sites/default/files/Old\%20Town\% 20season\%20ave\%202015.pdf>.

Fanasca, S., A. Martino, E. Heuvelink, and C. Stanghellini. 2007. Effect of electrical conductivity, fruit pruning, and truss position on quality in greenhouse tomato fruit. J. Hort. Sci. Biotechnol. 82(3):488-494.
Hanna, H.Y. 2009. Influence of cultivar, growing media, and cluster pruning on greenhouse tomato yield and fruit quality. HortTechnology 19:395-399.

Healy, G.K., B.J. Emerson, and J.C. Dawson. 2017. Tomato variety trials for productivity and quality in organic hoop house versus open field management. Renew. Agr. Food Syst. 32(6):562-572.

Kleinhenz, M.D. and N.R. Bumgarner. 2015. Using Brix as an indicator of vegetable quality: Instructions for measuring Brix in cucumber, leafy greens, sweet corn, tomato and watermelon. Ohio State Univ. Ext. 18 Sept. 2015. $<$ https://ohioline.osu.edu/factsheet/HYG-1651 $>$.

Maboko, M.M., C.P. Du Plooy, and S. Chiloane. 2011. Effect of plant population, fruit and stem pruning on yield and quality of hydroponically grown tomato. Afr. J. Agr. Res. 6(22):51445148.

Mefferd, A. 2017. The greenhouse and hoophouse grower's handbook: Organic vegetable production using protected culture. Chelsea Green Publishing, White River Junction, VT.

O'Connell, S., C. Rivard, M.M. Peet, C. Harlow, and F. Louws. 2012. High tunnel and field production of organic heirloom tomatoes: Yield, fruit quality, disease, and microclimate. HortScience 47:1283-1290.

Organic Trade Association. 2018. Organic Trade Association's 2017 organic industry survey. 14 Mar. 2018. <https://www.ota.com/news/pressreleases/19681>.

R Core Team. 2016. R: A language and environment for statistical computing. R Foundation for Statistical Computing, Vienna, Austria. 16 Jan. 2018. <https://www.R-project.org/>.

Rogers, M.A. and A.L. Wszelaki. 2012. Influence of high tunnel production and planting date on yield, growth, and early blight development on organically grown heirloom and hybrid tomato. HortTechnology 22:452462.

Saglam, N. and A. Yazgan. 1999. Effect of fruit number per truss on yield and quality in tomato. Acta Hort. 491:261-264.

Soil Survey Staff, Natural Resources Conservation Service, U.S. Department of Agriculture. 2018. Web soil survey. 24 Feb. 2018. <https:// websoilsurvey.sc. egov.usda.gov/>.

U.S. Department of Agriculture. 1991. U.S. standards for grades of fresh tomatoes. 12 Mar. 2018. <https://www.ams.usda.gov/ sites/default/files/media/Tomato_Standard\% $5 \mathrm{~B} 1 \% 5 \mathrm{D} . \mathrm{pdf}>$. 